\title{
The Improvement of Mathematical Problem- Solving Ability Through the Application of Problem-Based Learning Model on Students in Class VIII.1 SMPN 16 Solok Selatan
}

\author{
Denita Dikarina \\ Mathematics Department \\ Universitas Negeri Padang \\ Padang, Indonesia \\ denita.dikarina@gmail.com
}

\author{
Yerizon \\ Mathematics Department \\ Universitas Negeri Padang \\ Padang, Indonesia \\ yerizon@yahoo.com
}

\begin{abstract}
The cause of the lack of mathematical problemsolving ability of students in grade VIII.1 SMPN 16 Solok Selatan was because the learning model was still concentrated on the teacher. One effort that can be done to overcome this problem was to apply the PBL model. The objective of the study was to describe the process of improving students' mathematical problem-solving skills through learning with PBL model. The type of research was classroom action research. The study consisted of two cycles consisting of five meetings for each. The last meeting of each cycle was filled with the final test. This research consisted of four components, namely: action plan; action implementation; observation; and evaluation of the action (reflecting). The research was conducted on the students of class VIII.1 SMPN 16 Solok Selatan in the even semester of the academic year 2013/2014. Research subject amounted to 20 students. The collected data were analyzed descriptively. The result of this research indicated that there was an increase in problem-solving skills of mathematics students using the PBL model. The increase was seen from the increase of the average value of the final test cycle that examined the problem-solving and the percentage of mastery of student learning outcomes. It can be concluded that the PBL model can improve the problem-solving ability of students of grade VIII.1 SMPN 16 Solok Selatan in the even semester of the academic year 2013/2014.
\end{abstract}

Keywords-Improvement, Problem Solving Ability, PBL Model, Mathematics.

\section{INTRODUCTION}

Education is the process of guiding and teaching students so that there is a change in his/her mindset, attitude or behavior. Good education cannot be separated from a good learning process. Mathematics is one of the subjects that pays attention to the standard process and also the standard of content in improving the quality of learning. The competence standards that must be achieved by students are showing a logical attitude, critical, analytical, meticulous and thorough, responsible, responsive, and not easily give up in solving problems. Therefore, problem-solving activities are important activities that must be done by students in the learning process. It aims to improve mathematics problemsolving abilities. The success of a student in mastering the learning is also inseparable from his ability to solve problems.

The fact encountered in class-VIII students of junior high school (SMPN) 16 Solok Selatan shows different conditions with the expected situation. This can be seen from the low learning result of mathematics found in all class VIII including class VIII.1. Of the three daily tests of mathematics held in class VIII.1, not many students do it completely. When analyzed, it turns out that questions in form of daily life story become a problem for students. In addition to daily tests, students also have been given a problem-solving test twice. From the results of these tests, it is known that the students's mastery is still relatively low. In the first test, students's mastery is only $25 \%$ and in the second test is $30 \%$. Although students' mastery is increased, the increase is still relatively low. As mathematics problem-solving skills of students in class VIII.1 is low, it is need to do action research that can improve the mastery of learning.

Mathematics learning in class VIII.1 is still teachercentered. In the learning process, teachers always demand students to learn but teachers rarely give lessons how the students want to learn. Teachers also rarely require students to solve problems and rarely teach how should they solve the problem. This kind of learning always begins with material explanations using question and answer methods, giving examples of questions and exercises. While the teacher presents the material, the students only pay attention to the teacher and are asked whether they understand or not. Students are not involved in finding the concepts of the material. Students are also not given the opportunity to share ideas and discuss with fellow students so that students tend to be passive in following the learning. Problems given to the students are taken by the teacher from books as the teacher rarely tries to design problems related to the real world. The teacher give word problems, but only as the application of the concept.In addition, students are most often given routine questions in which the solution procedures are clear. Students are rarely familiarized with contextual stories. Not many problems that are less accustomed by the students to be 
interpreted into the language of mathematics. The problems given only need a direct process of completion that sometimes makes students less understood with the steps. Such learning conditions will not create a more conducive and meaningful learning environment for students. To overcome this problem, an appropriate learning model is needed. This model emphasizes the importance of cooperation in solving a problem.

One of the appropriate learning models to solve this problem is Problem-Based Learning (PBL) model. According to Forgaty, PBL is a learning that is designed using the real world where the problem is not well structured, open or ambiguous. Through this unstructured real-world problem, students are challenged to perform problem analysis, modeling, conducting experimental activities to perform problem solving [3]. In the PBL model, students are given non-routine problems or real-life story problems written in students' worksheet (LKS) and teachers as well as researchers guide students to find the solutions to their problems. This means that students learn based on the given problem. By making problems as a pedestal of learning, students are encouraged to seek what information is needed in solving the problem. Students are required and familiarized to seek ideas with their own awareness and initiative without being encouraged by others, running selfgenerated strategies until finding the right answers to the problem.

The PBL model is designed to help students develop thinking skills, problem solving, and intellectual skills. The objectives achieved by studying PBL models according to Ibrahim and Nur are (a) to help students develop thinking and problem-solving skills; (b) studying the various roles of adults through their involvement in real experience; (c) become autonomous students [2]. In order to achieve the purpose of PBL model, then all stages in the PBL model must be done well. Stages of the PBL model can be incorporated into the learning process as presented in Table $1[2]$.

\section{TABLE 1. THE STEPS OF PBL MODEL}

\begin{tabular}{|l|l|l|}
\hline No & Steps & Teacher Behavior \\
\hline a & $\begin{array}{l}\text { Student's orientation to the } \\
\text { problem }\end{array}$ & $\begin{array}{l}\text { The teacher explains the purpose } \\
\text { of the lesson, explains the } \\
\text { logistics required, motivates the } \\
\text { students to be involved in the } \\
\text { problem-solving activity they } \\
\text { choose. }\end{array}$ \\
\hline b & Organize students to learn & $\begin{array}{l}\text { Teachers help students define and } \\
\text { organize learning tasks related to } \\
\text { the problem. }\end{array}$ \\
\hline c & $\begin{array}{l}\text { Guiding individual and group } \\
\text { investigations }\end{array}$ & $\begin{array}{l}\text { Teachers encourage students to } \\
\text { gather appropriate information, } \\
\text { carry out experiments, to get a } \\
\text { problem-solving explanation. }\end{array}$ \\
\hline d & $\begin{array}{l}\text { Develop and present the } \\
\text { work }\end{array}$ & $\begin{array}{l}\text { Teachers assist students in } \\
\text { planning and preparing } \\
\text { appropriate works, such as: } \\
\text { reports, videos and models and } \\
\text { helping them to do their work } \\
\text { with friends. }\end{array}$ \\
\hline e & $\begin{array}{l}\text { Analyze and evaluate the } \\
\text { problem-solving process }\end{array}$ & $\begin{array}{l}\text { Teachers help students to reflect } \\
\text { on or evaluate their inquiry and } \\
\text { the processes they use. }\end{array}$ \\
\hline
\end{tabular}

The implementation of PBL model steps regularly and repeatedly during two cycles in learning can improve the ability to solve mathematical problems, because it always involves students actively in solving given problems so that the knowledge gained becomes more meaningful.

Problem solving ability is one of the cognitive abilities that must be possessed by students. In addition, the problem-solving ability is one of the general goals of mathematics and is even known as the heart of mathematics. Problem solving skills are also basic skills in learning mathematics. Therefore, the problem solving ability is necessary for the students.

To gain problem-solving skills, each student must have much experience in solving problems. Such experience can be gained through training. Various research results show that children who are given a lot of problem-solving exercises have a higher value in the problem-solving test than children who exercise less [4]. Problem solving skills will not develop automatically through the work of mathematics problems without being taught or guided by the teacher [1].

To cultivate mathematical problem-solving ability in students themselves, hence the teacher should try to design a problem which challenge and attract student to find the solution. Tthe characteristics of problem-shaped problems are (a) there are challenges in the material task or question; (b) problems can not be solved by using routine procedures; (c) the procedure of solving the problem is more than one way [6].

Director General of Higher Education Regulation no. (A) indicating the understanding of the problem; (b) organizing data and selecting relevant information in problem solving; (c) identifying problem; (b) organizing; data and selecting relevant information in problem; (c) presenting mathematics problems in various forms; (d) choosing appropriate approaches and problem-solving methods; (e) developing problem solving strategies; (f) creating and interpreting mathematical models of problems; (g) solving non-routine problems.

In addition to the indicators outlined by Dikdasmen, there is another mathematical problem-solving indicator, as follows: (a) Identify known elements, questions, and adequacy of required elements, (b) formulate mathematical problems or develop mathematical models; (c) implement strategies for solving various problems in or beyond mathematics, (d) explaining or interpreting the results according to the original problem, (e) using mathematics meaningfully [5].

The mathematical problem-solving indicators to be used in this research are as follows:

a. Understand the problem or identifying problems, such as by writing down the elements that are known, asked and the adequacy of the necessary elements

b. Formulate mathematics problems, such as choosing a strategy by sketching, composing a mathematical model or writing a formula.

c. Apply strategies to solve various mathematics problems.

d. Explain or interpret the results according to the original problem and conclusions by linking the results obtained with the problem in question. 
This is one of the features of the non-routine problem in which the solution requires many ways or strategies. In finding the strategy students have their own tricks, such as: trial and error; making diagrams; sketches; or other. In this case students have been using mathematics meaningfully.

\section{METHODS}

The research conducted was a classroom action research (PTK). This PTK used Kemmis and MC Taggart models through four stages, namely: action planning; action implementation; observation; and evaluation of the action result (reflection). The subjects of the research in this study were students of class VIII.1 SMPN 16 Solok Selatan consisting of 20 students.

Before the research was started, research tools such as lesson plan (RPP), student's worksheet (LKS) and test questions have been validated. The validator consisted of three people, namely two people from the faculty of mathematics majors FMIPA State University of Padang and one other person from the faculty of the department of Jambi University of Indonesia. The tool of this study was revised based on suggestions and inputs from validators, for later use. This study was conducted for two cycles. Cycle I consisted of four meetings closed with the first cycle test at the fifth meeting, while cycle II consisted of four meetings with the second cycle test at the tenth meeting. At the end of each cycle is given a mathematical problem solving test.

There were three kinds of instrument in this research, namely:

\section{Field notes.}

The field notes contained all-student's activity with the teacher in the classroom that dealt with aspects of mathematical problem-solving during the course of the study.

\section{Video recording}

Video recording was used to see the course of the learning process from the beginning to the end. The required video recordings were written into field notes to reinforce the data obtained and taken into consideration in the research reflection.

\section{Test the learning outcomes of each cycle}

The test of learning result for each cycle was used to determine the mathematical problem-solving ability.

\section{Exercise}

The exercise aimed to see how well students' development in solving problems.

Data of mathematical problem-solving ability in this research was got from the test of learning outcomes. The test of learning outcomes at each end of the cycle was designed in the form of a description that examined students' problem-solving ability. In this study, data analysis was done descriptively with the model miles and huberman. Data analysis used words that were always compiled in an extended text. Data analysis was started from the beginning of the research to the end and because the data analysis used the miles and huberman models. The steps that must be passed were to reduce the data or collect data by using the instrument, present the data either in narrative text or in the table and draw conclusions from the data. Prior to conclusion, the data obtained were re-tested with field data triangulated.

Data obtained from the test was analyzed by calculating the score of answers given by each student based on scoring rubric, then were processed using the percentage formula of individual's mastery. The result of this percentage was expected to be higher than the percentage of completeness level found in the preliminary data before the implementation of PBL model. Students were said being learning when their scores $\geq 60$.

\section{RESEARCH RESUlt AND DisCUSSION}

\section{A. The test result of mathematical problem-solving}

The results of the problem-solving tests given at the end of cycle I have not achieved the success indicators. New percentage of completeness reached $36.84 \%$ or 7 people out of 19 students completed the test. The implementation of PBL model in cycle I was much better. Students were getting used to this model but at some stages the PBL model was still not maximally implemented. Discussions were not yet fully operational because some couples did not match at all with their peers despite being given the understanding and direction. There were still many students who have not dared to come forward during the presentation and conclude the material. While doing exercises, very few students did it by themselves otherwise waited for cheating from friends.

Based on the reflection in cycle I, there was little change of action on the implementation of PBL model learning in cycle II. To overcome the problems in cycle I, the teacher tried to exchange the pair into groups by still paying attention to the academic ability and suitability of group members. This was aimed at the discussion can run maximally and students can share ideas to solve the problem. In addition, teachers also provided more problems about problem-solving to be done at home as an independent task that will be assessed. So, the students would more mathematics problem. For students who have not dared to come up with a variety of reasons, teachers tried to make a description with the expectations that all students can be better prepared when asked for a presentation or conclude the material. In addition, to avoid students do cooperating or cheating, the teacher provides a different question but still in the same indicator. Next, cycle II was applied. The test results in cycle II were much better and have improved than the final test result in cycle I. The results of the test revealed the success indicator had been achieved. Individual completeness had reached $57.89 \%$ or more than $55 \%$ of students had completed the test.

The development of students' mathematical problemsolving skills during cycle I was increasingly visible. This was apparent when the teacher had corrected the student practice result. From the practice of students in the first meeting of cycle I, almost most students had not been able 
to solve the problem well. Many students made mistakes while working on problem-solving questions. After the students were given direction and well guided, then at the next meeting until the last meeting of the cycle I, the problem-solving skills of students had improved. Many students can solve the problem step by steps. However, at the end of cycle I, the teacher kept doing reflection and attempted to change the action for cycle II in order to achieve the success indicator. After changes were applied in several meetings in cycle, then the cycle II was closed with a test to see students' problem solving ability. The result of the test revealed that almost all students had been able to solve the problem. Not many students made mistakes while doing every step of solution. Interestingly, more than 55\% or as many as $57.89 \%$ of students completed the problem.

\section{A. Discussion}

The PBL model is a learning model that focuses on learning of the problem. This model provides an opportunity for students to independently find problem-solving ideas so that the problem can be solved. The learning steps are arranged systematically so that problem solving as the objective of this learning can be achieved. Each student is accustomed to explain each other's ideas to a group of friends until they find the right idea to solve the problem.

In the mathematics learning that was conducted in class VIII.1 in SMP Negeri 16 Solok Selatan Kec. Sangir Batanghari has applied PBL model as an effort to improve problem-solving ability and learning independence of the student. The implementation of this model included five stages: 1) student orientation on the problem, 2) organizing students to learn, 3) guiding individual or group investigations, 4) developing and presenting the work, 5) analyzing and evaluating the problem-solving process. After implementing PBL model using the five stages, then there was an increase in problem-solving skills and the learning independence of students.

The improvement of problem-solving skills can be seen from the observation sheet supported by the results of the exercise for each meeting and test results at each end of cycle 1 and cycle 2 .

Implementation of learning with the PBL model in cycle I consisted of four meetings ended with the final test at the fifth meeting. The reflection on the first cycle turned out to show many positive developments. Although there were also some obstacles that must be solved as an improvement in the second cycle.

At the first meeting, many pairs of students objected to the division of groups chosen by the teacher. High-ability students did not want to be paired with low-ability students. Students who felt smart did not want to pair up with naughty students. Then, the teacher gave the briefing that each pair was given the same responsibility to explain each other's ideas to each other's partner. All couples except 3 couples accepted it and did not question it again at the next meeting. While that three couples still complained about the discomfort of their partners in the discussion until the fourth meeting. The teacher immediately discussed with the observer to find a solution for this problem.
The next problem occurred, in the problem orientation stage, while each student was faced with the problems written in student's worksheet (LKS) and asked to observe it. When asked to observe, only a few students did it seriously, meanwhile most couples still got much guidance and direction from the teacher. This was because students were unfamiliar with problem models, so they were less focused and less serious. With the guidance and direction given by the teacher, students seriously paid attention to the problem so that this problem can be overcome at the following meeting meeting.

At the stage of guiding the investigation in the PBL model, there was also a problem with a few couples who were still working on their own. This problem always occured in every meeting. Even though the teacher always gave direction, understanding, and affirmation, the three couples remained not optimal while discussing the reasons for their partner's incompatibility. They did not want to share ideas with their partners and were more likely to seek opinions on other couples. Meanwhile, most couples such as pairs I, II, III, VII, VIII and IX were looked seriously in explaining each other's ideas while working on LKS.

At the presentation stage, a problem occured in which not all couples were willing to perform presentation with their own initiative. Likewise when his friend presented the results of the discussion, none of the students raised their hands with their own initiative to provide suggestions or questions. This happened because they were afraid of being wrong and laughed at by friends. Given the guidance and motivation by the teacher continuously, then most of the students slowly become dared to be active for each meeting until the last meeting. Although there were still many students wanted to participate if requested only.

In the first cycle was more focused with the implementation of the stages of PBL model and to familiarize students to do self-learning independently when finding the ideas, and to be initiative to present, ask and comment on or independent while doing the exercises. Although, there had been an increase in terms of the development of some aspects of independent learning and problem-solving skills but not in accordance with the expected targets on the success indicators.

In cycle II, the implementation of PBL model had been increased. Students were able to follow every activity in this model with a focus because they were familiar with this kind of learning. Students also can work well together in the discussion, because the exchange of several couples into several groups had paid attention to the suitability of group members. Because the students were already familiar with this model and the friends for discussion were fit and comfortable, then the students had been able to focus and seriously follow all the learning steps so that the time provided has been utilized optimally.

The application of PBL model had had a positive impact on students' mathematical problem-solving abilities. The data obtained showed an increase from cycle I to cycle II. This can be seen from the correction of the exercise at the end of each meeting and the final test of each cycle.

The acquisition of training results at the first meeting was still less classical. Only small proportions of students 
had identified the problem and were able to choose a solution strategy by drawing a cube, defining the line that became the diagonal of the plane and writing the formula. However, most students still made many mistakes when identifying the problem. They wrote down the elements that were known to be incompatible with the given problem so that while solving the problem and showing the result they experienced a mistake as a result of misunderstanding the known element into the formula that they chose as the settlement strategy. Most students substituted any numbers into formulas that were supposed to be letters, which were already known. As a consequence, they cannot show the correct result. Overall, the lowest student ability was the student's ability when drawing conclusions. Most students cannot draw conclusions correctly and even worse the average student did not make any conclusions at all. This meant that they had not checked the answers they wrote to get a conclusion.

Classically, the results of the exercise at the second meeting increased. Most students had been able to write down important information from the problem and choose the right strategy while drawing the cube and writing the formula of the number of the edge of cube and the formula of the volume of the cube. But while solving problems, only very few students can show the results and draw the conclusions. This was because students cannot tamper with the written formula and they also did not equate the units before performing the calculations so that the solutions of the problem obtained were not correct. Similarly, when it came to conclusions, many students made an incomplete conclusion and wrong conclusions and even they emptied the box for writing the conclusions. Nevertheless, this condition had been better compared to the exercise at the first meeting.

For practice at the third meeting classically increased again. Already more than a half of number of students had been able to write important information on the problem, and, were able to find the right ideas as a problem solving. But for the indicator of drawing conclusions, there were still less than half of the number of students who can do it. Overall, it can be said that still less than half of students were able to solve the problem maximally.

The same with the fourth meeting, the results of the training experience increased again. Already more than a half of the number of students had been able to choose the peniting information from the problem, they can already write down what was known and asked correctly. For second indicator, choosing a strategy, was the most controlled indicators of students on the exercise 4. A lot of students correctly wrote down the idea of solving the problem. For the indicator of drawing conclusions, many students can do it compared to the previous exercise but the expected number of students doing it was still not as desired.

In the second cycle of exercise at the sixth meeting, it had not seen any significant increase and even the average value of problem-solving skills was almost the same as the exercise at the last meeting in cycle I. This was due to the adjustment of several newly changed groups so that communication between them was still not well established.
However, at the sixth meeting in the second cycle, the students who have finished the exercise were more than before.

The results of the exercise at the seventh meeting on the second cycle experienced a better change. The students completing it increased. The mistake made by many students was to determine the surface area of the prism and the volume of the prism. Students can only wrote broad formulas and prism volumes but they made mistakes in substituting appropriate numbers into the formulas and even they simply wrote the formulas without continuing the calculation process so that there was no solution they made.

For the exercise at the eighth meeting of cycle II, the students were already proficient in solving the problem made based on problem-solving indicators. Many of them can perform the counting operation and show the results correctly. They were also able to draw a full and correct conclusion. However, the number of students doing it completely was still the same as those in the previous exercise.

The same with the last exercise, in the last meeting of cycle II, many good changes and improvements happened. Students were accustomed to solving problems so that the problem-solving steps resolved were much better although there were still errors. This was shown by the number of students who completely solved the problem in which the number of students was more than expected that were 12 people or about $63.15 \%$. This means that more than a half of students have good mathematical problem solving skills.

Mathematical problem-solving tests at the end of cycle I had made progress and delivered better results than before. But the results obtained were still not in accordance with the expectation, which only 7 students $(36.84 \%)$ solved the problem completely.

Student answers still showed errors on each indicator set. Students were still less careful to understand the problem and in writing the settlement step. As a result, students cannot solve the problem correctly and completely. While in the final test of cycle II there was an increasing number of students who solved the problem completely, from 7 people to 11 people. If calculated, the percentage will be equal to $57.89 \%$. This amount was quite a lot and in accordance with the desired expectations in the indicator of success. However, students had not been able to reach a value of 100 and can only get the value of 92.5, which was achieved by one student only. This was caused by a rather high degree of material difficulty and students did not adequately analyze the problem. The improvement of mathematical problem-solving skills of students can be seen in Table 2.

Table 2. Percentage of Student's Learning COMPletion for EACH CYCLE

\begin{tabular}{|l|l|l|l|l|}
\hline \multirow{2}{*}{ Cycle } & \multicolumn{2}{|l|}{ A Completed Student } & \multicolumn{2}{l|}{ Unfinished Student } \\
\cline { 2 - 5 } & $\begin{array}{l}\text { Number of } \\
\text { (people ) }\end{array}$ & $\begin{array}{l}\text { Percentage } \\
(\%)\end{array}$ & $\begin{array}{l}\text { Number of } \\
\text { (people) }\end{array}$ & $\begin{array}{l}\text { Percentage } \\
(\%)\end{array}$ \\
\hline I & 7 & 36,84 & 12 & 63,16 \\
\hline II & 11 & 57,89 & 8 & 42,11 \\
\hline
\end{tabular}

Besides, the improvement of mathematical problemsolving ability for each indicator can be seen in Figure 1 . 


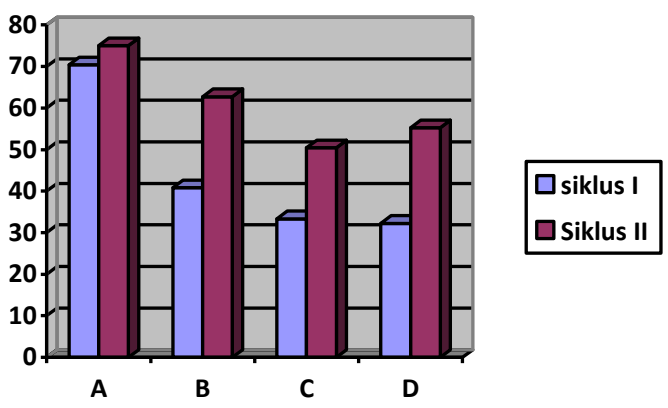

Fig. 1. Graph of Increasing Percentage of Problem Solving Ability per Indicators in Cycle I and Cycle II

Figure 1 showed the improvement of the mathematical problem-solving ability for each indicator in a classical manner. After cycle 1, the average of students' mastery of the first indicator (understanding the problem by identifying the problem) was $70,39 \%$. Then after cycle 2, It increased to $75 \%$. For the second indicator (formulating the problem by choosing the strategy), the average of student's mastery in the first cycle was $40.79 \%$ and after the second cycle, it increased to $62.72 \%$. For the third indicator (solving the problem), the increase of students' mastery also happened from $33.33 \%$ in the first cycle to $50.44 \%$ in the second cycle. The increase also occurred for the fourth indicator (drawing the conclusion) that was from $32,24 \%$ in the first cycle increased to $55,26 \%$ in second cycle.

\section{CONCLUSION}

The implementation of Problem-Based Learning model can improve mathematical problem-solving ability of grade VIII.1 students of SMP Negeri 16 Solok Selatan. When given the problems based on problem-solving indicators before the first cycle, the percentage of students' mastery was only $30 \%$. Then, at the end of the first cycle, it increased to $36.84 \%$ and at the end of the second cycle, it also increased to $57.89 \%$. The results of test analysis in the second cycle showed that the classical completeness level had reached more than $55 \%$. This meant that the success indicator to improve the mathematical problem-solving ability of students of grade VIII.1 SMP Negeri 16 Solok Selatan had been reached.

Students' responses to PBL learning model were very good. Many students responded that the PBL model can make them more confident so that they were more courageous to come forward without being asked. Besides, while doing the practice, they were able to solve the problem well according to the solution step. They also worked on their own without cheating from friends.

\section{SUGGESTION}

By considering the results of research and discussion, the following suggestions are worthwhile to be considered. 1. It is expected that mathematics teachers in SMP Negeri 16 Solok Selatan use PBL model continuously while still paying attention to the appropriate material so that mathematical problem-solving ability and independent learning grow more.

2. It is desirable that further research can be done on different subject and research sites by actually reviewing the conformity of the time allocation so that there are no other effects on the mismatch time allocation, which are determined.

3. In selecting the model of learning, teachers need to consider the characteristics of students, so that the model of learning used really can improve students' skills in solving mathematical problems and student's independent learning.

\section{REFERENCES}

[1] Fauzan, Ahmad, "Mathematical Problem Solving," (online), (http://evaluasimatematika.net accessed January 10, 2014), 2012.

[2] Rusman, "Learning Models," The Era of the Press. Bandung, 2012, pp 242-243.

[3] Sanjaya, W, "Standard-Oriented Learning Strategy," Kencana Prenada Media Group. Jakarta, 2009, pp.73.

[4] Suherman, Erman "The Strategy of Contemporary Mathematics Learning," Jica. Bandung, 2003, pp.93.

[5] Sumarmo, "Learning Independence: What, why and how it is developed in Learners Online," (http://math.spsi.upi.edu, accessed January 5, 2014)

[6] Wardhani, Sri "Implications of Mathematical Characteristics in Achieving Mathematics Subject Objectives in SMP / MTS," MoNE. Yogyakarta, 2010, pp.17. 